\title{
СОВРЕМЕННЫЕ ТЕНДЕНЦИИ НА РЫНКЕ ТРУДА С ТОЧКИ ЗРЕНИЯ ТЕОРИИ АЛЬТЕРНАТИВНЫХ ФИНАНСОВ
}

\section{() 2021 Будович Юлия Ивановна}

доктор экономических наук, доцент, профессор Департамента экономической теории Финансовый университет при Правительстве Российской Федерации, Россия, Москва

E-mail: JBudovich@fa.ru

ORCID: https://orcid.org/0000-0001-8691-947X

В настоящей статье доказывается наличие тенденции в современном мире, в том числе в нашей стране, вытеснения товарообменным трудом трансфертного труда в принципиально наблюдаемой зоне - когда это вытеснение выходит за рамки скрывающего его традиционного трудового договора и осуществляется в рамках трудовых отношений, подлежащих оформлению договорами гражданско-правового характера. Данная тенденция подтверждена развитием фриланса, аутстаффинга, производства товаров ручной работы, ростом доли труда, используемого производственными кооперативами.

Ключевые слова: фриланс, внутренний аутсорсинг, аутстаффинг, производство товаров ручной работы, производственный кооператив.

Одним из положений теории альтернативных финансов является положение о том, что альтернативные (товарообменные) финансы (системы ресурсообеспечения) являются более эффективными, чем традиционные (трансфертные) финансы, а именно более экономичными и доступными и менее токсичными, как для ресурсодателей, так и для ресурсополучателей, в связи с чем в мире идет, хотя и с переменным успехом, процесс вытеснения традиционных финансов их товарообменными альтернативами. Одной из систем ресурсообеспечения в экономике является система обеспечения фактором производства «труд», которая также представлена альтернативными трансфертными и товарообменными системами обеспечения. Для трансфертной системы характерно обеспечением трудом за плату, близкую к прожиточному минимуму, однако за это получатель труда должен сам обеспечить эффективное использование передаваемого ему работником труда в своих интересах и, кроме того, обязуется предоставить работнику социальные гарантии (оплата труда за время простоя, отчисления на обеспечение в старости и т.д.). Для товарообменной системы обеспечения трудом характерна значительно более высокая оплата труда - по цене его конечного продукта, но за это забота об эффективном использовании труда в интересах его получателя ложится на работника, и он лишается права требовать от работодателя каких-либо социальных гарантий. При этом, как и в общем случае, товарообменный труд является более эффективным (более экономичным, доступным и менее опасным), как для работника, так и для работодателя, в связи с чем должно иметь место вытеснение трансфертного труда товарообменным, процессы которого, однако, могут останавливаться или даже идти вспять из-за сопротивления, оказываемого трансфертным трудом товарообменному труду, в частности, через своих агентов, которым зачастую выступает трансфертное государство. В другой напечатанной в данном номере журнала «Экономические науки» статье Ю.И. Будович «Товарообменная трансформация трудовых отношений в рамках традиционного трудового договора» было показано, что одним из подтверждений наличия тенденции вытеснения трансфертного труда товарообменным выступает товарообменная трансформация труда, продаваемого по обычным трудовым договорам. В настоящей статье будет показано, что о вытеснении трансфертного труда товарообменным, идущем в мире и в нашей стране, говорят и другие процессы, происходящие на рынке труда, или процессы, их отражающие.

Ярким подтверждением тенденции замещения трансфертного труда товарообменным также является появление и ускоренное развитие фриланса, т.е. удаленной работы, исполняе- 
мой самозанятыми и подлежащей оформлению договорами гражданско-правового характера (ГПХ). В случае фриланса имеет место полное замещение трансфертного труда товарообменным трудом, происходящее на удаленке, не только потому, что считается, что фрилансер продает именно результат труда, но и потому, что получатель труда не предоставляет фрилансеру никаких социальных гарантий. Отсюда, фрилансу соответствует еще более значительное, чем при штатном телетруде, повышение платы за труд по сравнению с офисным трудом, осуществляющимся под управлением работодателя. Эксперты считают, что фрилансеры зарабатывают в 1,5-2 раза больше, чем их офисные коллеги [11].

Тенденцией последних лет стал резкий рост удаленной работы, исполняемой именно фрилансерами. Еще по данным за 2019 г., т.е. по допандемийным данным, компания $\mathrm{PwC}$ сделала прогноз, согласно которому глобальный рынок фриланса в 2020-2025 гг. будет расти со среднегодовым темпом 16\% [4]. Важно отметить, что в нашей стране еще до пандемии коронавируса произошел резкий рост удаленной работы, производимой фрилансерами. Согласно результатам также допандемийного исследования российского рынка фириланса, произведенного PwC, число фрилансеров у нас в 2014 г. составляло 3 млн. чел., в 2017-5, а на 2020 г. прогнозировалось в 14 млн. чел., Россия попала в топ-10 стран по объему рынка фриланса в денежном выражении, на 2020-2025 гг. прогнозировался рост российского рынка фриланса со среднегодовым темпом 20\% [4].

Следует отметить, что число фрилансеров или их доля в структуре занятости характеризует лишь вовлеченность населения во фриланс, отражая в том числе случайную подработку на фрилансе. Поэтому развитие фриланса лучше характеризует число или доля самозанятых фрилансеров. Согласно исследованиям фриланса, проводимым в нашей стране FL.ru coвместно с НИУ ВШЭ раз в несколько лет с 2009 г., доля чистых фрилансеров в общей численности фрилансеров в России неуклонно растет. Так, в 2009 г. она составляла $22 \%$, в 2011-29, в 2014-34, а в 2019 г.- уже $52 \%$ [2].

Важно отметить, что главной причиной развития удаленной работы (как штатных сотрудников, так и фриланса) является вовсе не развитие IT-технологий, в частности распространение интернета, а именно более высокая эффектив- ность товарообменного труда по сравнению с трансфертным (или труда с большей долей товарообменного труда). Так, ученые Стэнфорда в течение 2 лет изучали удаленный труд в туристической компании Ctrip (Китай) и пришли к выводу, что он дал 13-процентный прирост производительности [5, с. 142]. Как было показано в вышеуказанной статье Ю.И Будович, удаленный труд появился после 1972 г., тогда как широкое распространение интернета в мире началось только в самом конце 1990-х гг. [6]. Между тем, уже в 2000 г., например, в Великобритании число телеработников (работающих вне офиса как минимум 1 день в месяц) составляло 4 млн. чел., или $15 \%$ от общей численности занятых, в США 11 млн. чел., или 8,5\% от общей численности занятых [13, с. 132].

Также важно отметить, что вовсе не коронавирус вызвал глобальное переосмысление рынка труда, как это преподносят, например, эксперты Bloomberg, отмечая, что коронавирус заставил людей срочно перейти на дистант, а после снятия ограничений компании под впечатлением этого перехода в массовом порядке стали вводить гибридный график, сочетающий работу в офисе и дистант, а также 4-дневную рабочую неделю [19]. Главной причиной переосмысления рынка труда в сторону удаленной работы является та же более высокая эффективность удаленного труда, выступающая отражением более высокой эффективности товарообменного труда по сравнению с трансфертным. Это переосмысление началось задолго до пандемии коронавируса. К началу 2020 г. 16\% мировых компаний использовали полностью удаленную занятость, а 40\% - комбинированную [5, с. 142]. Так что пандемия коронавируса могла только ускорить соответствующий процесс - путем навязывания опыта дистанционной работы.

Как было показано выше, эксперты предсказывают в ближайшие годы опережающий рост удаленной работы, прежде всего фриланса, выступающего товарообменным удаленным трудом. Вместе с тем, представляется, что развитие удаленного труда имеет границы, и сомнительно, что в обозримом будущем основная часть работников организаций (в масштабах страны) сможет работать удаленно или, точнее, большая часть труда сможет передаваться организациям удаленно. Возможно, рост фриланса в развитых с точки зрения удаленного труда странах уже сдерживается объективными границами теле- 
труда в обществе. Отсюда следует, что победу товарообменному труду над трансфертным может принести лишь соответствующая трансформация офисной занятости (рассматриваемой широко, т.е. и как занятости в производственных помещениях работодателя). Напомним, что товарообменный труд отличается от трансфертного, помимо значительно более высокой оплаты, лишь полной ответственностью работника за результат труда и отсутствием у работника социальных гарантий от работодателя, так что, с точки зрения теории альтернативных финансов, гражданско-правовые отношения работников с работодателями легко могут иметь место не только вне офиса, но и в офисе. Именно на борьбу с гражданско-правовой трактовкой, прежде всего, офисных трудоотношений направлены усилия российского государства, о чем говорит соответствующая судебная практика. Так, судами в трудовые правоотношения переквалифицируются, например, услуги по уборке помещений и труд кочегаров котельных, в первую очередь, на том основании, что они представляют собой не разовые работы, а оказание услуг в течение длительного периода времени [9]. С точки зрения теории альтернативных финансов, такая позиция государства сдерживает, как рост эффективности труда офисных (в том числе производственных) работников, так и мобильность рабочей силы в стране, замедляя экономический рост. Прорыв в развитии товарообменного труда в офисе, по нашему мнению, готовит развитие аутсорсинга работ, выполняемых в офисе заказчика, когда те передаются на исполнение сторонним организациям, и, прежде всего, технологических (не таких, как, например, уборка помещений) производственных (не управленческих, как например бухгалтерский учет) работ. Последние активно передаются на аутсорсинг, например, в порядке развития партнерских отношений с поставщиками. Так, в Бразилии в Резенде на заводе Volkswagen, выпускающем грузовые автомобили, основным поставщикам передали часть рабочих площадей, которые теперь сами устанавливают на грузовики поставляемые ими узлы, а служащие Volkswagen, которых на заводе стало меньшинство, только контролируют деятельность поставщиков и качество готовой продукции $[18$, с. 766$]$. Подобный «внутренний» аутсорсинг возникает также в порядке реализации концепции концентрации на ключевых направлениях и передачи непрофиль- ных процессов на аутсорсинг, когда, например, машиностроительные предприятия отказываются от замкнутого цикла производства, при котором осуществляются все стадии производства, и оставляют у себя лишь основное производство, передавая на аутсорсинг литейное, штамповочное и пр. производство [10]. Аутсорсинг фактически обосновывается тем, что работодатель не в состоянии обеспечить эффективное управление трансфертным трудом в непрофильных процессах, которое могут обеспечить лишь специализированные работодатели, т.е. непосредственно речь идет не о замене трансфертного труда товарообменным, а о переподчинении трансфертного труда. Однако для работодателя, внедряющего аутсорсинг, последний означает замену низкоэффективного трансфертного труда аналогичными, но более эффективными, товарообменными услугами, оказываемыми, правда, не работниками, а сторонними организациями. При этом государство, бизнес и работники приучаются к тому, что услуги и продукция внутри организаций, прежде всего в их производственных помещениях, могут производиться не по трудовым договорам, а по договорам ГПХ, что продукты такого производства обходятся организациям дешевле, оно более доступно и менее опасно, и что перечень соответствующих товарообменных продуктов постоянно расширяется. В условиях же, когда в организациях развивается исполнение интеллектуальноуправленческих процессов работниками по договорам ГПХ (хотя и, в основном, на удаленке), остается лишь один шаг к пониманию того, что и внутренние производственные процессы, передаваемые на аутсорсинг, могут исполняться по договорам ГПХ самими работниками, а не представляющими их организациями. Таким образом, если развитие внутреннего аутсорсинга и не является непосредственным отражением тенденции замены трансфертного труда товарообменным, то все же является для государства, бизнеса и самого труда школой товарообменной (в отличие от трансфертной) организации производства в помещениях работодателя. Развитие внутреннего производственного аутсорсинга с организациями, таким образом, неизбежно приближает то время, когда по договорам ГПХ в помещениях работодателей в массовом порядке будут работать рабочие не только вспомогательных производств, но и основного производства. Да и развитие товарообменного труда в рамках 
традиционного трудового договора неизбежно когда-то должно разорвать соответствующе оковы и принять подобающую ему форму договора ГПХ.

Ярким подтверждением тенденции вытеснения трансфертного труда товарообменным является развитие аутстаффинга, когда работники, фактически работающие в офисе (в широком смысле, т.е. и в производственных помещениях) работодателя и под его управлением, числятся в штате специализированного агентства. Аутстаффинг получил широкое распространение в мире. Так, в Японии лишь 1/3 сотрудников (топ-менеджеры и ключевые сотрудники) числится в штатах компаний. Международные компании в странах пребывания обычно используют работников, привлекаемых через аутстаффинг. В нашей стране в конце 2019 г. через аутстаффинг трудились почти 18 млн. работников (в том числе в производстве и на складах - 5,1 млн. чел., клининге $-3,3$, розничной торговле $-2,6$, строительстве $-2,1$, охране $-1,7$, логистике $-1,4$, кафе и ресторанах - 1,3) [1]. При общей численности занятых в нашей стране в конце 2019 г., равной 72,4 млн. чел. [24], это 25\% (18/72,4*100) от их числа.

Как было показано выше, у товарообменного труда, помимо его полной оплаты, 2 отличительных признака - полная ответственность работника за продукт труда и полное отсутствие у работника социальных гарантий от работодателя. Аутстаффинг как раз и позволяет получателю труда избавиться от бремени социальных гарантий. Передаваемый работодателям по аутстаффингу труд, хотя и продолжает требовать большего или меньшего управления с их стороны, но лишается такого признака трансфертного труда, как предоставление социальных гарантий работникам. Правда, сами работники без социальных гарантий не остаются, поскольку бремя последних теперь лежит на компаниях-аутстафферах. Однако за счет того, что компания-аутстаффер, работающая с множеством работодателей с зачатую одинаковыми потребностями в труде, имеет возможность быстро найти работнику нового (фактического) работодателя, реальный груз социальных гарантий, лежащий на бизнесе, в масштабах общества существенно снижается.

Обеспечение трудом по аутстаффингу является более доступным, экономичным и менее опасным для получателей труда по сравнению с обеспечением обычным трансфертным тру- дом. При аутстаффинге получатель труда может быстро подобрать нужных работников, экономит на содержании кадровой и бухгалтерской служб больше, чем теряет на надбавке за аутстаффинг, в случае исчезновения потребности в труде не несет издержек, связанных с исполнением предоставленных работникам социальных гарантий, например может мгновенно отказаться от их труда и не оплачивать время простоя. Обеспечение трудом по аутстаффингу является более доступным, экономичным и менее опасным и для получателей труда. При аутстаффинге работник имеет возможность быстро получить работу, может выбрать работу ближе к дому, снижая тем самым свои удельные затраты на единицу трудового дохода, может без потери дохода пережить ситуацию, когда получатель труда теряет потребность в его труде, так как компания-аутстаффер может быстро подыскать ему другую аналогичную работу.

Подтверждением наличия в мире тенденции замещения трансфертного труда товарообменным трудом является и такое явление, как рост производства товаров ручной работы, выступающих продукцией, прежде всего, ремесленников, представляющих собой работников, продающих результаты труда и не имеющих социальных гарантий от заказчиков, т.е. работников товарообменного труда. О росте в мире производства товаров ручной работы можно судить по показателям деятельности Etsy - крупнейшего международного маркетплейса товаров ручной работы, продажи которого за 2020 г. выросли в 2 раза, достигнув 10 млрд. долл. США, что лишь частично объясняется всплеском производства медицинских масок ручной работы в начале пандемии коронавируса. Если в 2017 г. общий доход Etsy составил 441 млн. долл. США, то в 2018 г. он достиг 604 млн. долл. США, в 2019818, а в 2020-1726! [21] Существенный рост демонстрирует производство товаров ручной работы и в нашей стране. Аналогичная компания в нашей стране Ярмарка мастеров - Livemaster в мае 2020 г. провела исследование новых трендов, выявившихся с начала 2020 г., и установила, что на платформе стали покупать в 10 раз больше сумок из ткани, в 4 раза больше - одежды, в 3 раза больше - игрушек из природного сырья [15].

Подтверждением наличия в мире тенденции замещения трансфертного труда товарообменным трудом является и стремительное развитие кооперации, в том числе производственных 
кооперативов (ПК), или артелей. По данным Worldwatch Institute, число членов кооперативов в 2012 г. достигло 1 млрд. чел., при общей численности населения в том году 7 млрд. чел. По нашим подсчетам, с начала века по 2012 г. включительно число членов кооперативов в мире увеличилось на 25\%, тогда как население мира выросло только на 16\%. Среди экспертов сложилось мнение, что в современной истории нет социально-экономической организации, которая по темпам распространения сравнилась бы с кооперативом, в связи с чем мировая экономика даже стала рассматриваться как трехсекторная, т.е. состоящая из государственного, частного и кооперативного секторов [3, с. 234]. При прочих равных условиях, опережающий рост кооперативного сектора означает и опережающий рост деятельности ПК и, следовательно, труда, получаемого ПК.

С точки зрения теории альтернативных финансов, сущностью ПК является товарообменная капитальная система (система наделения предприятия собственным капиталом при его создании и расширении), так как топ-менеджмент классического ПК, которым выступают все его учредители, в полной мере оплачивает имущество, получаемое им в собственность (в отличие, например, от топ-менеджмента классического акционерного общества, который такое имущество получает в свое полное распоряжение абсолютно бесплатно). Соответствующее имущество вследствие его полной оплаты приобретает в глазах топ-менеджмента ПК адекватную ценность, что побуждает его проявлять должную заботу о сохранности и количественном и качественном приращении имущества ПК. При этом члены классического ПК, помимо того, что объединяют личное имущество, объединяют еще и свой труд, приводящий в действие имущество ПК. Очевидно, что забота о максимально эффективном использовании имущества ПК в этих условиях совпадает с заботой о максимально эффективном использовании своего труда на благо ПК, которая и представляет собой управление личным трудом в целях максимизации полезности его продукта для организации. Отсюда следует, что члены ПК передают ПК интересующие его конечные продукты их труда, т.е. производственный труд членов ПК в этом отношении является товарообменным. Да и никто из артельщиков не захочет объединять свой труд с трудом лица, которое не отвечает за конечный продукт своего труда, или не обеспечивает необходимого количества и качества этого продукта, т.е. кормить бездельника. И, подобно тому, как, участвуя в непосредственном управлении имуществом предприятия, члены ПК претендуют на значительно более высокий доход от переданного предприятию имущества, чем участники акционерного общества, так и, передавая ПК не трудовую функцию, а интересующие ПК результаты их труда, они вполне обоснованно претендуют и на значительно более высокую оплату своего труда. Признаком же более высокой платы членам ПК, как за переданное ими ПК имущество, так и за переданный ими ПК труд, является сам характер получаемого членами ПК дохода, которым является прибыль ПК - члены ПК, как и бизнесмены, учредившие предприятие в форме товарищества, получают часть прибыли кооператива - оставшуюся после уплаты налогов и других обязательных платежей и направления прибыли на иные цели, определяемые общим собранием членов кооператива [22]. Признаком товарообменного характера производственного труда членов классического ПК выступает и то, что они работают в ПК, не заключая с ним трудовых договоров, трактовка юридической наукой труда в ПК как формы самозанятости населения [17], а также полная ответственность членов ПК по обязательствам ПК, когда в случае, если ПК не может расплатиться с кредиторами, его члены обязаны сообща гасить задолженность ПК личными средствами или имуществом [23]. Юридические же признаки трансфертного характера производственного труда членов ПК, которыми выступают, например, то, что члены ПК подлежат социальному страхованию и обеспечению наравне с наемными работниками ПК, на них заводится трудовая книжка [14], являются уже отмечавшимся выше искажением юридической формой реальных производственных отношений, в данном случае - трудовых отношений между трудящимися членами ПК и самим ПК.

Таким образом, производственный труд членов ПК (артели) является товарообменным трудом, а опережающий рост ПК по сравнению с остальной экономикой также говорит о вытеснении товарообменным трудом трансфертного труда. Следует отметить, что использование товарообменного труда является дополнительным фактором эффективности ПК, объясняющим, почему ПК, выступая, как и централизованно управляемое государственное предприятие, 
предприятием с товарообменной формой собственности, является более эффективным, чем это госпредприятие, что подтверждает сравнение эффективности функционирования колхозов и совхозов в СССР [3, с. 235].

В наших работах отмечалось, что при изучении тенденции вытеснения товарообменным трудом трансфертного труда особое значение приобретает проверка соответствия реальным производственным отношениям их юридической формы, которая зачастую искажает эти реальные отношения и даже сдерживает их прогрессивное развитие. Кстати, проследить успехи производственной кооперации в нашей стране не позволяет, прежде всего, юридическая форма, в данном случае - юридическая форма системы ресурсообеспечения «капитал». Так, официальная российская статистика предприятий, базирующаяся на их юридической трактовке, показывает, что в 2003 г. в нашей стране было 14,4 тыс. производственных сельскохозяйственных кооперативов, что составляло $50,4 \%$ от общей численности сельскохозяйственных предприятий, но с 2004 г. их количество стало быстро сокращаться, упав до 4,5 тыс. в 2015 г., или до $22,2 \%$ от общего числа сельхозпредприятий (18\% сельхозугодий) [12, с. 107]. Эти данные, казалось бы, противоречат отмеченной выше тенденции опережающего развития ПК в экономике. Однако, как выясняется, сокращение доли ПК в сельскохозяйственном производстве России происходило не в результате разорения и закрытия соответствующих предприятий, а вследствие их переоформления в общества с ограниченной ответственностью и акционерные общества. Причиной смены организационно-правовой формы выступила низкая инвестиционная привлекательность производственных кооперативов - инвестору сложно влиять на их деятельность из-за демократического принципа управления «1 член -1 голос» [12, с. 108]. Виновато в этом, прежде всего, государство, которое не предусмотрело юридических механизмов, обеспечивающих равный интерес инвесторов к предприятиям разных форм собственности. Понятно, что в подобных случаях смена формы предприятия может вовсе не означать изменения реальных трудовых отношений между ним и его работниками.

Как уже отмечалось, юридическим отражением наличия у труда товарообменной и трансфертной альтернатив является существование двух типов договоров трудового найма - договора ГПХ и трудового договора соответственно. Отсюда следует, что важнейшим свидетельством замещения трансфертного труда товарообменным должны выступать данные официальной статистики труда о структуре занятости на основной работе по характеру договора. Однако до последнего времени (в которое еще не вошло время пандемии коронавируса) эти данные не говорили ничего о замещении в стране трансфертного труда товарообменным трудом. Они показывали, что доля договоров ГПХ в занятости на основной работе растет в периоды бурного экономического роста и падает в периоды экономических кризисов, демонстрируя стабильность в периоды незначительных спадов экономики или ее незначительного роста. И на самом деле, по крайней мере, в последние годы 10-летнего периода бурного экономического роста в России 1999-2008 гг. наблюдался рост доли договоров ГПХ в структуре работающих по найму на основной работе, которая увеличилась с 1,8\% в 2006 г. до 2,1 - в 2007 и 2,2 - в 2008 (при этом росла и доля работающих на основе устной договоренности, увеличившись с 3,8\% в 2006 г. до 4,2 - в 2008) [16, с. 47], а в кризисные годы и годы восстановления наблюдалось существенное снижение соответствующей доли, а именно до 1,4\% в 2009 г., 1,1 - в 2010, 1,0 - в 2011 (снижалась и доля работающих на основе устной договоренности, сократившись до 3,8\% в 2009 г. и до 3,5 - в 2011) [16, с. 47], что легко объясняется снижением у наемных работников страха за будущее в период бурного экономического роста и усилением такого страха у них в период экономического спада соответственно. В «обычное» же время, а именно в период 2013-2019 гг., доля работающих по договорам ГПХ на основной работе показала стабилизацию на уровне 0,9-1,2\% (а доля работающих на основе устной договоренности - на уровне 3,7-4,0\%) [16, с. 47]. Однако, эти данные очевидным образом не соответствуют приводившимся выше данным о бурном развитии в нашей стране фриланса, которое началось за несколько лет до появления коронавируса (число фрилансеров вырастет с 5 млн. чел. в 2017 г. до 14 млн. чел. в 2020, доля самозанятых фрилансеров в их общем числе составила в 2019 г. 52\%). Если число фрилансеров в России прирастает на 3 млн. чел. в год ((14-5)/3), то в 2019 г. оно должно было составить 11 млн. чел. $(5+(3 * 2))$, из которых 5,7 млн. $\left(11^{*} 52 / 100\right)$ 
должны были быть самозанятыми, т.е. работать по договорам ГПХ. Даже прибавив к доле работающих по договорам ГПХ долю работающих по устной договоренности, вместе составляющие около $5 \%((0,9+1,2+3,7+4,0) / 2=4,9)$ от $72,4 \mathrm{Mлн.}$ чел. занятых на конец 2019 г. (см. выше), получим лишь 3,6 млн. чел. всех работников страны (не только фрилансеров), работающих по договорам ГПХ. Объяснением того, что официальная статистика договоров ГПХ в структуре занятости не отражает развития самозанятого фриланса в нашей стране является, во-первых, его развитие в рамках скрытой экономики, т.е. без оформления договорами, и, во-вторых, развитие в России фриланса по заказам иностранных организаций. Чтобы стать официальным фрилансером, работающим по договору об оказании услуг, работнику нужно оформить статус индивидуального предпринимателя (ИП) или самозанятого [8], а по данным Национальной гильдии фрилансеров только 26\% фрилансеров оформили этот статус и только 29\% планируют это сделать [20]. Что касается работы на иностранных заказчиков, то по данным опроса, проведенного в середине 2017 г. Аналитическим центром НАФИ, за год число фрилансеров в России увеличилось с 10 до 18\% (для $11 \%$ фриланс стал единственным источни- ком дохода), т.е. их доля в занятости фактически выросла за год почти в 2 раза $(18 / 10=1,8)$, а проведенное тогда же совместное исследование Data Insight и PayPal показало, что $2 / 3$ российских фрилансеров работают с зарубежными заказами, главным образом с таковыми из США, Великобритании и Германии [7], т.е. этот рост целиком мог состояться за счет иностранных заказов.

Говоря о роли статистики договоров ГПХ в структуре занятости на основной работе в отражении процесса замещения трансфертного труда товарообменным трудом в целом, заметим, что она не покажет увеличения товарообменного элемента в трудовых отношениях, оформляемых трудовыми договорами, роста чистого товарообменного труда, но из-за запретов или по незнанию оформляемого трудовыми договорами, будет слабо отражать замещение трансфертного труда товарообменным вследствие развития фриланса и производства товаров ручной работы (по причине работы на удалении от заказчика), и в полной мере сработает как индикатор процесса замещения трансфертного труда товарообменным в обществе лишь тогда, когда товарообменный труд начнет побеждать трансфертный труд в офисе.

\section{Библиографический список}

1. Аутстаффинг работников - тонкости технологии / Центр Миг. URL: https://centrmig.com/articles/autstaffingrabotnikov-tonkosti-tekhnologii (дата обращения: 22.09.2021).

2. Барулин Е. День фрилансера в России: как изменился фриланс за десять лет / vc.ru. 14.05.2019. URL: https:// vc.ru/hr/67084-den-frilansera-v-rossii-kak-izmenilsya-frilans-za-desyat-let (дата обращения: 16.10.2021).

3. Будович Ю. И. Кооперативы как альтернативная «нефинансовая» система ресурсообеспечения // Экономические науки. 2020. № 11 (192). С. 231-240. DOI: 10.14451/1.192.231.

4. Gig-экономика / PwC. Февраль 2021 г. URL: https://www.pwc.ru/ru/publications/freelance-platform/pwc freelance_market_research_final.pdf (дата обращения: 06.10.2021).

5. Гурова И. М. Дистанционная работа как тренд времени: результаты массового опыта // МИР (Модернизация. Инновации. Развитие) 2020. Т. 11. № 2. С. 128-147.

6. История развития интернета / История Вещей. URL: https://clubhistory.ru/internet/istoriya-razvitiyainterneta.html (дата обращения:16.10.2021).

7. Камнева К. Сам по себе сотрудник / Российская газета. RG.RU. URL: https://rg.ru/2017/12/05/chemobiasniaetsia-uvelichenie-chisla-frilanserov.html (дата обращеня: 04.10.2021).

8. Кто такие фрилансеры: подробное описание и обзор / checkroi. 06.01.2021. URL: https://checkroi.ru/blog/ktotakoy-frilanser-i-chem-zanimaetsya/ (дата обращения: 30.09.2021).

9. Липина М.А. В чем отличия договора ГПХ от трудового договора? / Audit-it.ru. 13.10.2021. URL: https:/www. audit-it.ru/articles/account/court/a51/1021435.html (дата обращения: 22.09.2021).

10. Лихачев, В.А. Внутренний аутсорсинг как корпоративный инструмент инновационного развития / В. А. Лихачев, М. Р. Арсланов. - Текст: непосредственный // Проблемы и перспективы экономики и управления: материалы IV Междунар. науч. конф. (г. Санкт-Петербург, декабрь 2015 г.).- Санкт-Петербург: Свое издательство, 2015.- С. 147-149. - URL: https://moluch.ru/conf/econ/archive/171/9145/ (дата обращения: 17.10.2021).

11. Маркелов А. Кто такой фрилансер, ТОП-30 самых востребованных фриланс-профессий / Как Заработать. Путеводитель по заработку. 15.07.2021. URL: https://guruzarabotka.ru/frilanser/ (дата обращения: 30.09.2021). 
12. Минаков И. А. Сельскохозяйственные производственные кооперативы и перспективы их развития в России // Технологии пищевой и перерабатывающей промышленности АПК-продукты здорового питания, 2017. Т. 3. C. $105-113$.

13. Никуткина К.М., Привалова А.О. Западные количественные исследования фрилансеров: профессиональный обзор // Экономическая социология. Т. 10. № 1. Январь 2009. С. 127-143.

14. Производственный кооператив. Плюсы и минусы. Примеры из практики / клерк. 28.05.2020. URL: https:// www.klerk.ru/buh/articles/500174/ (дата обращения: 29.10.2021).

15. Пфанштиль И. Какие handmade товары выбирают покупатели в 2020 году. Исследование / rusability.ru. 20.05.2020. URL: https://rusability.ru/news/kakie-handmade-tovari-vibirayut-pokupateli-v-2020-godu-issledova nie/5fd2968a2dda593c3483edd8 (дата обращения: 17.10.2021).

16. Рабочая сила, занятость и безработица в России (по результатам Р13 выборочных обследований рабочей силы). 2020. Стат. сб. / Росстат.-М., 2020. 145 с.

17. Регистрация юридического лица / ЭЕ. Эксперт Лигал Эдвайс. Expert Legal Advice. URL: https://allc.ru/ registraciya-yuridicheskih-lic-predprinimatelei/ (дата обращения: 14.08.2020).

18. Робинс С.П., Коултер М. Менеджмент / Пер. с англ.-М.: Вильямс, 2004. 880 с.

19. Рынок труда после пандемии - каким он будет? / Skillbox Media. 28.04.2021. URL: https://skillbox.ru/media/ management/rynok_truda_posle_pandemii_kakim_on_budet/ (дата обращения: 08.10.2021).

20. Сапожникова М. Свобода по выбору: настоящее и будущее фриланса в России / РБК. Тренды. 17.06.2021. URL: https://trends.rbc.ru/trends/social/60c8e3139a79472ba64fde35 (дата обращения: 30.09.2021).

21. Стась А. Мировой рынок крафтовой продукции стремительно растет / Ведомости. 01.03.2021. URL: https:// www.vedomosti.ru/opinion/articles/2021/02/28/859589-mirovoi-rinok (дата обращения: 17.10.2021).

22. Статья 106.3. Имущество производственного кооператива / Гражданский кодекс РФ. Новая редакция и комментарии к ней. URL: https://gkrf24.ru/statia-106.3-gk (дата обращения: 17.08.2020).

23. Субсидиарная ответственность члена кооператива / МОСЮРКОНСАЛТ. Многопрофильный холдинг. URL: https://mosyurconsult.ru/articles/subsidiarnaya-otvetstvennost-chlena-kooperativa/ (дата обращения: 30.08.2020).

24. Число занятых в экономике составило 10-летний антирекорд / Финмаркет. 09.02.2021. URL: http://www. finmarket.ru/main/article/5407853 (дата обращения: 17.10.2021). 